last year, I picked one near a train station and in a town where we can walk to everything, because one of the first things I will do if my vision loss progresses much further is to take myself off the road. I can't see my own feet when I walk, so I always hold on to a railing or someone else when I descend. I can't see people's mouths move when I stand a comfortable distance away from them during a conversation, so I sometimes have trouble hearing. I often can't see gestures people make with their hands. I can't see my fingers as I type this. But what's most distressing is that I will never again be able to see, up close, the entirety of someone's face.

\section{My ways of coping}

I do question why I was not diagnosed earlier. I have myopia and have been to see an ophthalmologist almost yearly since I was 10 . During the regular eye examinations I was sometimes even "tested for glaucoma"-that is, tested for elevated intraocular pressures. But I can only remember receiving one dilated eye examination in my life, when I was in my late teens. And no health practitioner ever asked me simply to close one eye, look at a fixed spot in the room, and notice whether anything was missing.

Fortunately, up to now I have been able to live without much aid. I have considered joining a glaucoma support group, but given the age of the typical glaucoma patient, I am hesitant. To calm my own fears, I empower myself by learning as much as possible about the disease's theories, treatments, and outcomes. I work at a medical college, so I have ready access to and read all the literature on glaucoma. I have not been reticent to seek second opinions, for which I have flown to Florida and telephoned an expert in Switzerland. I have sought out complementary and alternative treatments. But there is no way to judge whether unconventional therapies are having any beneficial effect, and there are distinct limits to what I will try. Nevertheless, all of these things I do to remain somewhat in control of a situation that is almost completely out of my control. In the long run I believe the only thing I can do is to remain the expert about my own eyes.

\section{My journey's end}

At any age increasing vision loss is incredibly frightening and debilitating, but facing this prospect so early in

\section{What I need along the way}

I have used the internet to gather basic information about glaucoma. Here are some of the websites I have found most useful

- www.nlm.nih.gov/medlineplus/glaucoma.htmlprovides links to many other sites on specific glaucoma related topics

- www.glaucomafoundation.org/index.php-gives an overview of the disease, provides answers to common questions, and provides links to other sites

- www.nei.nih.gov/health/glaucoma/glaucoma facts.asp-defines the disease and its causes, symptoms, and treatment and contains links to publications - www.glaucoma.org-provides information about glaucoma, living with the disease, and treatments, as well as an overview of some current research

\section{My companion on the journey: Douglas Rhee's perspective}

I am Christine's ophthalmologist. When I first met her she already had significant damage in both eyes with moderate (by conventional standards) visual field loss. I thought that it was unusual for someone as young as she was to have developed low tension glaucoma (glaucoma with intraocular pressures that are within the statistically average range); however, the diagnosis was clear. I started out quite optimistic, as we have numerous treatments, but became more despondent as each drug we tried and added failed to have any effect in lowering her intraocular pressures.

Studies estimate that about $25 \%$ of people with glaucoma receiving state of the art care will still go blind in one eye and $10 \%$ will go blind in both eyes (that is, functionally blind) despite all our technology. I choose to specialise in glaucoma in part because of those daunting statistics: I want to help to stop the harm from the disease, or from the treatments themselves. Doctors are, however, susceptible to marginalising patients who "fail" treatments, because there is the potential to view the situation as personal failure. Nevertheless, even after treatments fail or someone goes blind, there is still the potential to offer healing. The patient's life still goes on, and perhaps that is when they need us the most.

I have spent my career trying to convey my genuine compassion and to be a good healer. However, Christine's story made me understand how limited I and other doctors are, in some cases because of the time pressures induced by a managed care system, and in most cases because we often don't fully understand what it is to have glaucoma. Even if we have heard the descriptions of "fog" or "misty" (or worse yet "dark"), we never truly know about the actual impact of these visual deficits. Christine's detailed and emotionally open descriptions made the condition more real for me. I have continually striven to understand from patients the impact of glaucoma, and I even lecture to doctors on what it is that patients "see" and the physiological basis for compensatory mechanisms, yet I did not have a complete picture until I heard Christine's testimony.

Christine and I have walked hand in hand, trying to pursue treatments that make medical sense and that also work with her overall life plan. I am relieved that her rate of decline has been very slow, giving us time to wait for new discoveries rather than forcing our hand towards a surgical method to lower her intraocular pressures. I stand ready to take the next step of conventional glaucoma surgery if we both decide that this has become necessary. Until that day I continue to endeavour in the laboratory to help develop some of those new treatments to some day help Christine and others like her. Although we save the sight of most, we still need to do a better job.

life adds another layer of complexity. Nevertheless, I have hope for the future: hope that understanding of glaucoma will progress to the point that treatments will no longer be shots in the dark, hope that the medical system will increase its flexibility and support of those of us who have to visit clinics frequently for chronic conditions, and hope that education of medical staff will increasingly emphasise a more holistic perspective. The uncertainties of the present I intend to confront with confidence in my own abilities and the help of the companions on my journey. After all, a patient with glaucoma or not, I still have a life to live.

Competing interests: None declared.

(Accepted 13 September 2006)

doi $10.1136 /$ bmj.38975.507188.7C

\section{After the cure}

Every patient is a doctor after his cure. Irish proverb

Submitted by Prakash Saha, senior house officer in surgery, St Helier's Hospital 